\title{
Dioscin suppresses the viability of ovarian cancer cells by regulating the VEGFR2 and PI3K/AKT/MAPK signaling pathways
}

\author{
XIANQING GUO $^{1}$ and XIAO DING ${ }^{2}$ \\ Departments of ${ }^{1}$ Pharmaceuticals and ${ }^{2}$ Gynecology and Obstetrics, \\ Qilu Hospital of Shandong University, Qingdao, Shandong 266035, P.R. China
}

Received November 5, 2016; Accepted September 28, 2017

DOI: $10.3892 / \mathrm{ol} .2018 .8454$

\begin{abstract}
Diosgenin is a natural steroidal saponin that is extracted from a range of sources, including from fenugreek. It is a critical raw material in the synthesis of steroid hormone drugs, exhibiting antitumor, anti-inflammatory, antioxidation and a number of other significant pharmacological actions, possessing high pharmaceutical value. The aim of the present study was to investigate the effects of dioscin suppression on ovarian cancer cell growth and the mechanism of apoptosis induction by dioscin in ovarian cancer cells. The results of the present study demonstrated that dioscin decreased viability and induced apoptosis in SKOV3 human ovarian cancer cells in a dose-dependent manner. Dioscin significantly increased caspase- 3 and caspase- 9 activity, and increased the protein expression of Bax and cleaved poly(ADP-ribose) polymerase in SKOV3 cells. In addition, dioscin significantly suppressed vascular endothelial growth factor receptor (VEGFR)2, phosphoinositide 3-kinase (PI3K), phosphorylated AKT and phosphorylated p38 mitogen-activated protein kinase (MAPK) protein expression in SKOV3 cells. Taken together, to the best of our knowledge, the present study demonstrated for the first time that dioscin suppresses cell viability in ovarian cancer cells by regulating the VEGFR2 and PI3K/AKT/MAPK signaling pathways.
\end{abstract}

\section{Introduction}

Ovarian cancer is one of the three most common types of malignant tumors of the female reproductive system (1). It accounts for $\sim 25 \%$ of female genital system neoplasms (2),

Correspondence to: Dr Xiao Ding, Department of Gynecology and Obstetrics, Qilu Hospital of Shandong University, 758 Hefei Road, Qingdao, Shandong 266035, P.R. China

E-mail: xikar20114@126.com

Key words: dioscin, ovarian cancer cells, vascular endothelial growth factor receptor 2, phosphoinositide 3-kinase/protein kinase B, mitogen-activated protein kinase with the highest mortality rate. In addition, according to official statistics, the incidence of ovarian cancer is increased in 2012 in China (1). The majority of patients with ovarian cancer are diagnosed with the disease at an advanced stage (3) and therefore, are not suitable for treatment by surgical resection due to pelvic cavity, intraperitoneal and lymphatic metastasis, and adjacent organ infiltration (4). In cases such as these, disease progression can only be controlled by relying on chemotherapeutics: however, the results are not ideal, as the survival rate is low (4). Conversely, patients diagnosed at an early stage of ovarian cancer can be treated with a cytoreductive surgery and combined chemotherapy regimen based on uranium and paclitaxel, which is associated with a relatively improved survival rate (3). Therefore, early diagnosis is a critical factor for the effective treatment of ovarian cancer.

The vascular endothelial growth factor receptor (VEGFR)2/VEGF signaling pathway serves a vital function in the angiogenesis of ovarian cancer (5) and is the primary target for antitumor angiogenesis therapy. VEGF has been demonstrated to be a pro-angiogenic factor (6). It promotes angiogenesis by inducing the growth and migration of endothelial cells, promoting the formation of vascular endothelial cells and increasing the permeability of blood vessels (7).

The downstream effects of EGFR activation primarily comprises two major signal transduction pathways: Ras/Raf/mitogen-activated protein kinase kinase (MEK)/extracellular signal-regulated kinase (ERK) and phosphoinositide 3-kinase (PI3K)/AKT, which are being increasingly studied (8). Previous studies have demonstrated that EGFR signaling primarily induces tumor cell proliferation and differentiation through the Ras/Raf/MEK/ERK signaling pathway and promotes the survival of tumor cells through the PI3K/AKT signal transduction pathway (9). Raf-1 and AKT are two important kinases in the two aforementioned pathways (10), with previous studies identifying that they are hubs for signal transduction and potentially effective targets for the treatment of ovarian cancer $(10,11)$.

Mitogen-activated protein kinase (MAPK) is an important intracellular signal transduction system for the transfer extracellular information to the cell nucleus, thus participating in and affecting a variety of physiology and pathological processes (12). p38MAPK and ERK1/2 are essential members 
of these signal transduction pathways (13). It has been demonstrated that the p38MAPK and ERK1/2 signaling pathways serve essential functions in tumor incidence, drug resistance and metastasis regulation (14). The p38MAPK signal transduction pathway is associated with drug resistance in patients with ovarian cancer (14) and may also be associated with drug resistance in gastric cancer cells (13).

Diosgenin, commonly known as saponin, is a natural and synthetic steroid sapogenin (Fig. 1) (15). The relative molecular mass of diosgenin is $414.63 \mathrm{~g} / \mathrm{mol}$. Diosgenin is present at high levels in leguminosae and dioscoreaceae plants. It is an essential raw material for the synthesis of steroid hormone drugs and steroidal contraceptives (15). In the past few decades, in-depth studies on the pharmacological actions of diosgenin have been performed (16). Diosgenin has exhibited antitumor, blood lipid-regulating, anti-platelet aggregation and bilifaction promotion effects (16). It can be used as a drug for the treatment of cardiovascular disease, encephalitis, dermatosis and tumors (17). The present study aimed to investigate the effect of dioscin treatment on ovarian cancer cell growth and the mechanisms for apoptosis induction by dioscin in ovarian cancer cells.

\section{Materials and methods}

Cell line and cell culture. The ovarian cancer cell line SKOV3 was obtained from the Experiment Center of Shandong University (Shandong, China) and was cultured in minimum essential medium $\alpha$ (Promega Corporation, Madison, WI, USA) containing $10 \%$ fetal bovine serum (Gibco; Thermo Fisher Scientific, Inc., Waltham, MA, USA), 100 U/ml penicillin and $100 \mu \mathrm{g} / \mathrm{ml}$ streptomycin (Sigma-Aldrich; Merck $\mathrm{KGaA}$, Darmstadt, Germany) at $5 \% \mathrm{CO}_{2}$ and $37^{\circ} \mathrm{C}$.

Cell viability and apoptosis assays. SKOV3 cells were seeded into a 96-well-plate $\left(1 \times 10^{3}\right.$ cells/well) and treated with 0 , $1.25,2.5$ and $5 \mu \mathrm{M}$ of dioscin for 24,48 and $72 \mathrm{~h}$. Following dioscin stimulation, MTT was added to each well $(0.5 \mathrm{mg} / \mathrm{ml}$ final concentration) and incubated for $4 \mathrm{~h}$ at $37^{\circ} \mathrm{C}$. Then, old medium was removed and $150 \mu \mathrm{l}$ dimethyl sulfoxide (99.99\%) was added for the dissolution of formazan crystals. The absorbance was measured at $492 \mathrm{~nm}$ by an iMark ${ }^{\mathrm{TM}}$ microplate reader (Bio-Rad Laboratories, Inc., Hercules, CA, USA).

To investigate apoptosis, SKOV3 cells were seeded into a 6-well-plate $\left(1 \times 10^{6}\right.$ cells/well) and treated with $0,1.25,2.5$ and $5 \mu \mathrm{M}$ of dioscin for $48 \mathrm{~h}$. Subsequently, cells were washed with PBS and stained with Annexin V-FITC/PI (5 $\mu \mathrm{l} /$ well; Nanjing KeyGen Biotech Co., Ltd., Nanjing, China) for 15 min in darkness at room temperature. The rate of apoptosis was measured using a FACSCalibur ${ }^{\mathrm{TM}}$ machine with Image Lab (version 3.0; Bio-Rad Laboratories, Inc.) and analyzed with ModFIT software (Verity Software House, Inc., Topsham, ME, USA).

Caspase-3 and caspase-9 activity. SKOV3 cells were seeded into a 6 -well-plate $\left(1 \times 10^{6}\right.$ cells/well) and treated with $0,1.25$, 2.5 and $5 \mu \mathrm{M}$ of dioscin for $48 \mathrm{~h}$. Subsequently, cells were washed with PBS and lysed in radioimmunoprecipitation assay (RIPA) buffer (Beyotime Institute of Biotechnology, Haimen, China). Following $30 \mathrm{~min}$ of incubation at $37^{\circ} \mathrm{C}$, the lysed cells were then centrifuged at $3,000 \mathrm{x} \mathrm{g}$ for $10 \mathrm{~min}$ at $4^{\circ} \mathrm{C}$ to pellet large cellular debris. A total of $5 \mu \mathrm{g}$ of the pellet was incubated with caspase- 3 and caspase- 9 activity kits (Beyotime Institute of Biotechnology) for $1.5 \mathrm{~h}$ at $37^{\circ} \mathrm{C}$, according to the manufacturer's protocol. The absorbance was measured using an iMark $^{\mathrm{TM}}$ microplate reader at $405 \mathrm{~nm}$.

Western blot analysis. SKOV3 cells were seeded into a 6-well-plate $\left(1 \times 10^{6}\right.$ cells/well) and treated with $0,1.25,2.5$ and $5 \mu \mathrm{M}$ of dioscin for $48 \mathrm{~h}$. Subsequently, cells were washed with PBS and lysed in RIPA buffer (Beyotime Institute of Biotechnology). Following $30 \mathrm{~min}$ of incubation, the lysed cells were centrifuged at $3,000 \mathrm{x}$ for $10 \mathrm{~min}$ at $4^{\circ} \mathrm{C}$ to pellet large cellular debris. Total protein extracted was quantified with a BCA Protein Assay kit (Beyotime Institute of Biotechnology). The samples $\left(50 \mu \mathrm{g} /\right.$ per lane) were heated at $100^{\circ} \mathrm{C}$ for $5 \mathrm{~min}$, loaded onto 6-12\% SDS-PAGE gels for electrophoresis and then transferred onto a polyvinylidene difluoride membrane (Bio-Rad Laboratories, Inc.). Membrane was blocked with $5 \%$ non-fat milk in TBST for $1 \mathrm{~h}$ at $37^{\circ} \mathrm{C}$. Following incubation with the primary antibodies, including anti-Bax (cat. no. sc-6236; 1:500), anti-cleaved poly(ADP-ribose) polymerase (PARP; cat. no. sc-1562; 1:500; both Santa Cruz Biotechnology, Inc., Dallas, TX, USA), anti-VEGFR2 (cat. no. 9698; 1:2,000; Cell Signaling Technology, Inc., Danvers, MA, USA), anti-PI3K (cat. no. sc-7174; 1:500), anti-p-AKT (cat. no. sc-7985-R; 1:500), anti-phosphorylated p38MAPK (cat. no. sc-17852-R; 1:500) and anti-GAPDH (cat. no. sc-25778; 1:5,000; all Santa Cruz Biotechnology, Inc.) overnight at $4^{\circ} \mathrm{C}$, the membranes were washed with TBST and incubated with horseradish peroxidase-conjugated goat anti-rabbit IgG secondary antibody (1:5,000; cat. no. BA1054; Wuhan Boster Biological Technology, Ltd. Wuhan, China) for $1 \mathrm{~h}$ at $37^{\circ} \mathrm{C}$. Protein bands were detected by an enhanced chemiluminescence kit (Beyotime Institute of Biotechnology) and quantified by LabWorks software (version 4.0; Bio-Rad Laboratories, Inc.).

Statistical analysis. Statistical significance throughout the present study was analyzed using one-way analysis of variance and Tukey's post hoc test. Values are presented as the mean \pm standard deviation from three replicates using SPSS 17.0 (SPSS, Inc., Chicago, IL, USA). P<0.05 was considered to indicate a statistically significant difference.

\section{Results}

Dioscin treatment decreased the viability of SKOV3 cells. The effects of different doses $(0,1.25,2.5$ or $5 \mu \mathrm{M}$ for 24 , 48 and $72 \mathrm{~h}$ ) of dioscin on the viability of human ovarian cancer SKOV3 cells was investigated using an MTT assay. As presented in Fig. 2, dioscin treatment significantly decreased reduced the viability of human ovarian cancer SKOV3 cell in a dose- and time-dependent manner compared with the untreated control $(\mathrm{P}<0.01)$.

Dioscin treatment induced apoptosis in SKOV3 cells. To study the anticancer effects of dioscin, the rate of apoptosis in SKOV3 human ovarian cancer cells was measured following treatment with $0,1.25,2.5$ and $5 \mu \mathrm{M}$ of dioscin for $48 \mathrm{~h}$ with flow cytometry. Compared with the $0 \mu \mathrm{M}$ control group, dioscin 


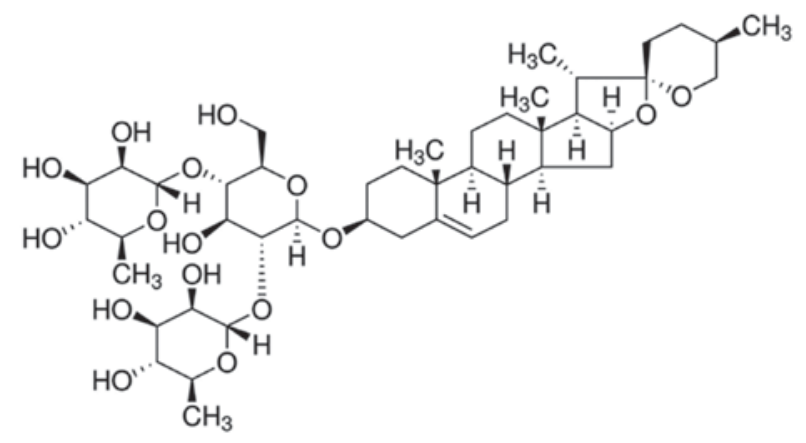

Figure 1. Structural formula of dioscin.

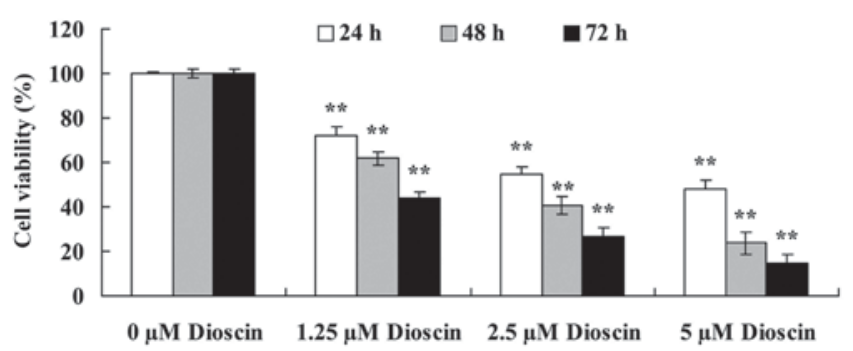

Figure 2. Effects of dioscin treatment at distinct concentrations and treatment times. Dioscin decreased cell viability in SKOV3 human ovarian cancer cells. ${ }^{* *} \mathrm{P}<0.01$ vs. $0 \mu \mathrm{M}$ dioscin group.

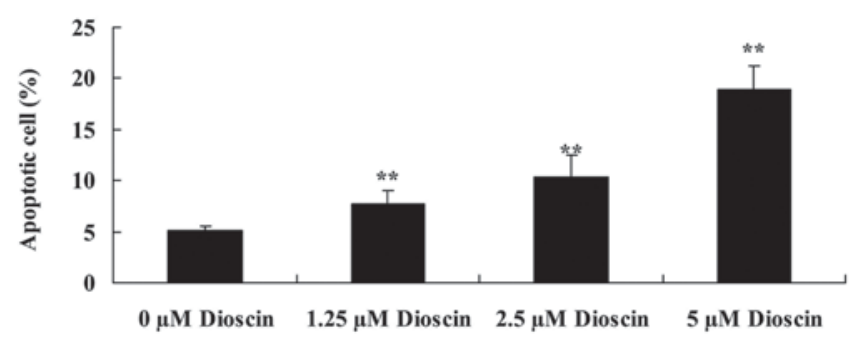

Figure 3. Dioscin treatment induced the apoptosis of SKOV3 human ovarian cancer cells in a dose-dependent manner. ${ }^{* *} \mathrm{P}<0.01$ vs. $0 \mu \mathrm{M}$ dioscin group.

significantly increased cellular apoptosis in a dose-dependent manner ( $\mathrm{P}<0.01$; Fig. 3).

Dioscin treatment promoted caspase-3 and caspase-9 activity in SKOV3 cells. In order to investigate the endogenous regulatory function of caspase- 3 and caspase- 9 in human ovarian cancer, the present study measured caspase-3 and caspase-9 activity in SKOV3 cells. As presented in Fig. 4, caspase- 3 and caspase- 9 activity in the SKOV3 cells was significantly increased following treatment with 1.25 , 2.5 or $5 \mu \mathrm{M}$ dioscin, compared with the untreated control $(\mathrm{P}<0.01)$.

Dioscin treatment increased Bax and cleaved PARP protein expression in SKOV3 cells. To explore the anticancer effects of dioscin in human ovarian cancer, Bax protein expression level was determined using a western blot analysis. Western blot analysis demonstrated that the effects of dioscin $(1.25,2.5$ or $5 \mu \mathrm{M})$ significantly increased Bax and cleaved PARP protein expression levels in SKOV3 cells, compared with the untreated control group $(\mathrm{P}<0.01$; Fig. 5).

Dioscin treatment suppressed PI3K/AKT, VEGFR2 protein expression and induced p-p38 protein expression in SKOV3 cells. To investigate the role of PI3K/AKT, VEGFR2 and p-p38 in the anticancer effects of dioscin treatment of SKOV3 cells, the present study performed western blot analysis. As presented in Fig. 6, treatment with $2.5 \mu \mathrm{M}$ or $5 \mu \mathrm{M}$ dioscin significantly suppressed PI3K and phosphorylated (p)-AKT, VEGFR2 protein expression, and induced p-p38 protein expression in SKOV3 cell, compared with the control group $(\mathrm{P}<0.01)$.

\section{Discussion}

Primary epithelial ovarian cancer is the most fatal type of malignant gynecological tumor, with a global fatality rate of $\sim 6.2 \%$ (4). In 2012, there were 22,000 new cases of ovarian cancer and $\sim 15,500$ associated mortalities in the United States (4). This high mortality rate is due to chemotherapy resistance and the lack of effective screening methods (18). Although $>70 \%$ of patients with ovarian cancer can be treated effectively with surgery, chemotherapy and second-line chemotherapy, novel and more effective pharmacological intervention is required due to the low overall cure rates and serious adverse effects associated with chemotherapy (19). The results of the present study indicated that dioscin significantly promoted caspase- 3 and caspase- 9 activity, increased Bax protein expression and enhanced cleaved PARP protein expression in SKOV3 cells.

VEGF mediates cell synthesis, stimulates cellular proliferation and migration, and enhances the permeability of blood vessels through the effects of VEGFR on vascular endothelial cells (20). Local increases in VEGF concentration may promote the upregulation of the expression of vascular endothelial cell VEGFR, which is an important mechanism to allow VEGF in tumor tissue to promote angiogenesis (20). VEGFR2 is highly expressed on the endothelial cell surface of new blood vessels in a tumor, and promotes the growth of the new endothelial cells required by tumor angiogenesis (21). The expression percentage and expression intensity of VEGFR2 is considered to be an important indicator for the evaluation of tumor prognosis (22). Consequently, VEGFR2 is an essential factor for tumor anti-angiogenesis therapy (22). The results of the present study demonstrated that treatment with dioscin significantly suppressed VEGFR2 protein expression in SKOV3 human ovarian cancer cells compared with the untreated control group. A previous report by Tong et al (15) suggested that dioscin inhibits colon tumor growth through regulating VEGFR2 signaling pathways.

EGFR and its ligands extensively exist on epithelium, stroma, original nerve cells and various microstructures (23). EGFR is activated by dimerization and phosphorylation following the binding of exogenous substrates; in turn, it activates the downstream Ras/Raf/MAPK and Ras/PI3K/AKT/mTOR signaling pathways, thus controlling a variety of the biological responses of mature tissues (24). In addition, EGFR and the associated pathways are essential in embryonic development and tissue differentiation (24). EGFR serves an important function 

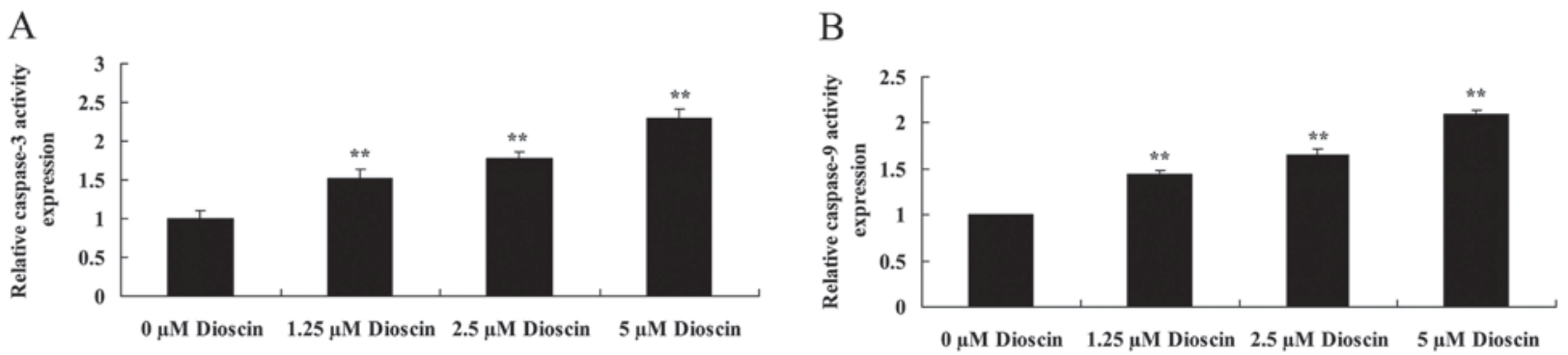

Figure 4. Dioscin treatment promoted (A) caspase-3 and (B) caspase-9 activity in SKOV3 human ovarian cancer cells. ${ }^{* *} \mathrm{P}<0.01$ vs. $0 \mu \mathrm{M}$ dioscin group.
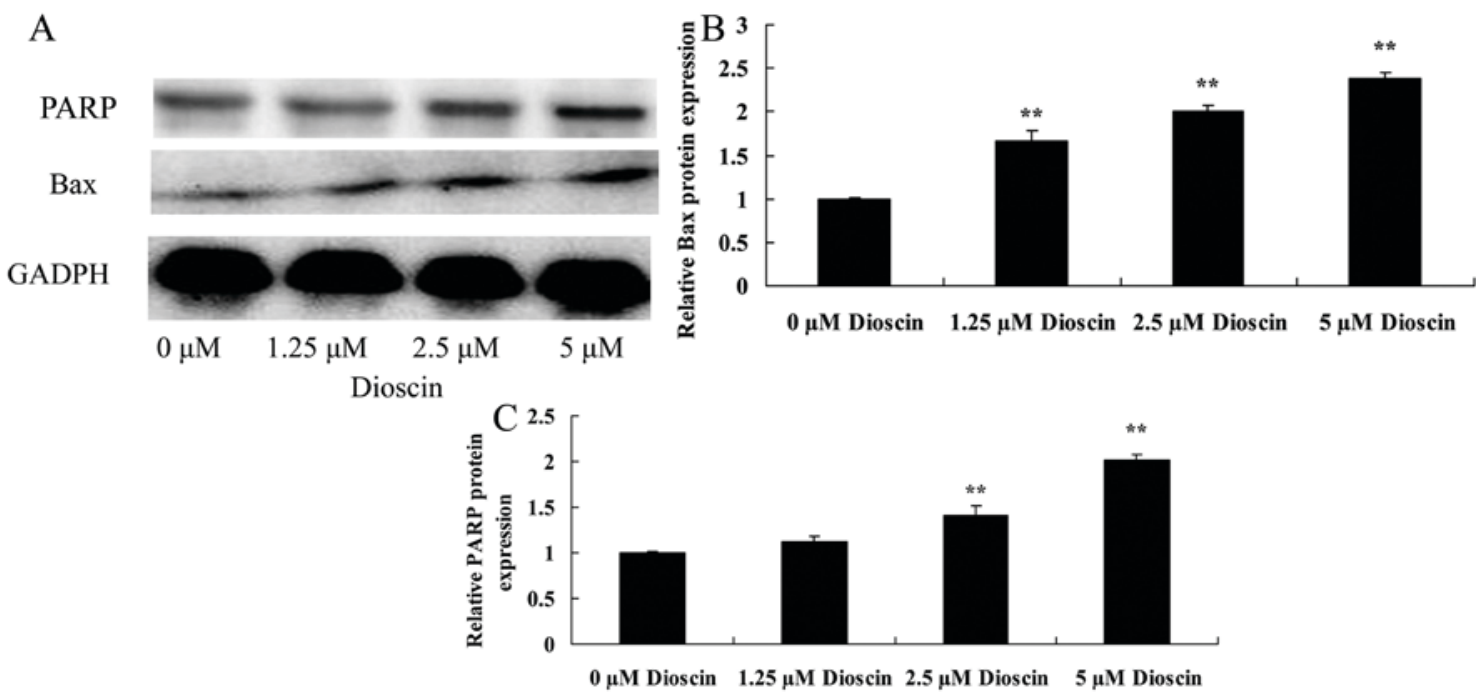

Figure 5. Dioscin treatment increased Bax and cleaved PARP protein expression in human ovarian cancer SKOV3 cells in a dose-dependent manner. (A) The effect of dioscin treatment on Bax and cleaved PARP protein expression were investigated using western blotting, which demonstrated that (B) Bax and (C) cleaved PARP protein expression were decreased in SKOV3 human ovarian cancer cells treated with dioscin. ${ }^{* *} \mathrm{P}<0.01$ vs. $0 \mu \mathrm{M}$ dioscin group. Bax, Bcl2-associated X, PARP, poly(ADP-ribose) polymerase.
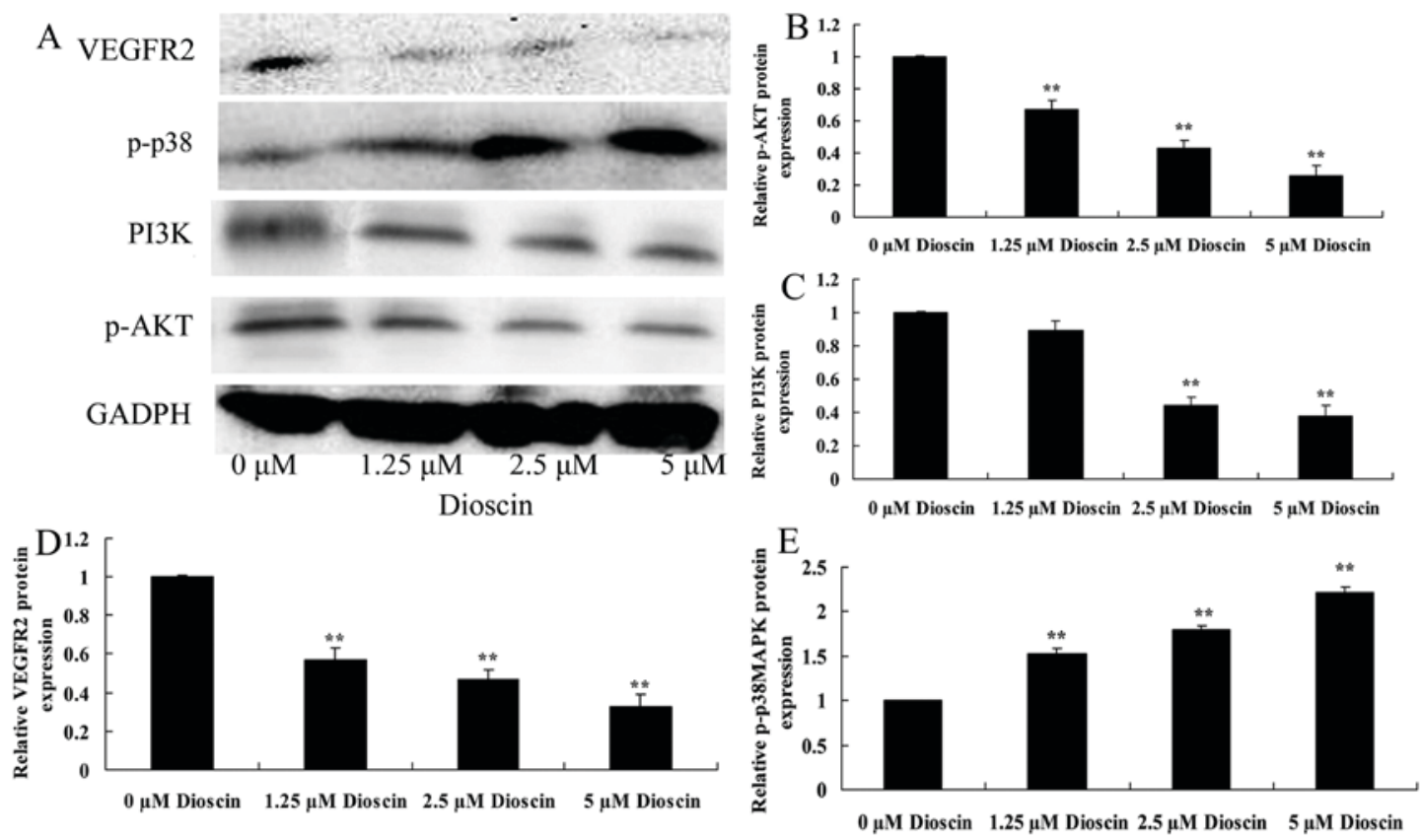

Figure 6. Dioscin treatment suppressed PI3K/AKT, VEGFR2 protein expression, and induced p-p38 protein expression in SKOV3 human ovarian cancer cells. (A) The effect of dioscin treatment on PI3K, p-AKT, VEGFR2 and p-p38 protein expression were investigated using western blotting, which demonstrated that (B) p-AKT, (C) PI3K, (D) VEGFR2 and (E) p-p38 protein expression were decreased in SKOV3 human ovarian cancer cells treated with dioscin. ${ }^{* *} \mathrm{P}<0.01 \mathrm{vs.} 0 \mu \mathrm{M}$ dioscin group. PI3K, phosphoinositide 3-kinase; p-AKT, phosphorylated AKT; VEGFR2, vascular endothelial growth factor receptor; p-, phosphorylated. 
in regulating the growth and differentiation of normal cells as well as promoting the growth of tumor and mesenchymal cells, tumor cell adhesion and apoptosis resistance, and tumor metastasis and angiogenesis (25). In addition, previous studies have demonstrated that the overexpression of EGFR is associated with drug resistance in ovarian cancer (25). The results of the present study revealed that dioscin significantly suppressed $\mathrm{PI} 3 \mathrm{~K}$ and $\mathrm{p}-\mathrm{AKT}$ protein expression in SKOV3 cells, compared with the untreated control group. Hsieh et al (26) demonstrated that dioscin induced human lung cancer cell apoptosis through modulation of the PI3K/Akt signaling pathway.

The effect of number of growth factors and receptors associated with tumor growth and metastasis processes is mediated via the p38MAPK signaling pathway (27). Tumors are generated as a response to the dysregulation of intracellular signaling (27); the p38MAPK pathway is an essential signaling pathway for the transduction of signals to the nucleus (28), with functions in cell growth, proliferation, cell death, cell cycle, inflammation and stress reactions (29). In addition, the p38MAPK signal transduction pathway may inhibit tumor formation (30) and regulate the synthesis of interleukin (IL)-1 $\beta$ precursor, thus promoting IL-1 $\beta$ synthesis (31). IL-1 $\beta$ coordinates immunological function, activating lymphocytes to promote proliferation, promoting the generation of antibodies and activated cytokines, enhancing the cytotoxicity of natural killer cells and creating a positive feedback effect that effectively kills tumor cells (31). The results of the present study indicated that treatment with dioscin significantly induced the p-p38 MAPK protein expression of SKOV3 human ovarian cancer cells compared with the untreated control group. In accord with this result, Wang et al (17) demonstrated that dioscin induced the apoptosis of HL-60 acute myeloid leukemia cells through the activation of p38MAPK and Jun N-terminal kinase.

In conclusion, the results of the present study demonstrated for the first time, to the best of our knowledge, that dioscin suppresses cellular viability and induces apoptosis in ovarian cancer cells through the suppression of the VEGFR2 and PI3K/AKT/p38 MAPK signaling pathways. Thus, dioscin may have potential as an anticancer drug, and the VEGFR2 and $\mathrm{PI} 3 \mathrm{~K} / \mathrm{AKT} / \mathrm{p} 38 \mathrm{MAPK}$ signaling pathway may represent a potential target for anticancer agents.

\section{Acknowledgements}

Not applicable.

\section{Funding}

No funding was received.

\section{Availability of data and materials}

The analyzed data sets generated during the study are available from the corresponding author on reasonable request.

\section{Authors' contributions}

XD designed the study. XG performed the experiments. XG and XD analyzed the data. XD wrote the manuscript.

\section{Ethics approval and consent to participate}

Not applicable.

\section{Consent for publication}

Not applicable.

\section{Competing interests}

The authors declare that they have no competing interests.

\section{References}

1. Ren Y, Shi T, Jiang R, Yin S, Wang P and Zang R: Multiple cycles of neoadjuvant chemotherapy associated with poor survival in bulky stage IIIC and IV ovarian cancer. Int J Gynecol Cancer 25: 1398-1404, 2015.

2. Falandry C, Weber B, Savoye AM, Tinquaut F, Tredan O, Sevin E, Stefani L, Savinelli F, Atlassi M, Salvat J, et al: Development of a geriatric vulnerability score in elderly patients with advanced ovarian cancer treated with first-line carboplatin: A GINECO prospective trial. Ann Oncol 24: 2808-2813, 2013.

3. Fisher M and Gore M: Cost-effectiveness of trabectedin plus pegylated liposomal doxorubicin for the treatment of women with relapsed platinum-sensitive ovarian cancer in the UK: Analysis based on the final survival data of the OVA-301 trial. Value Health 16: 507-516, 2013.

4. Kehoe S, Hook J, Nankivell M, Jayson GC, Kitchener H, Lopes T, Luesley D, Perren T, Bannoo S, Mascarenhas M, et al: Primary chemotherapy versus primary surgery for newly diagnosed advanced ovarian cancer (CHORUS): An open-label, randomised, controlled, non-inferiority trial. Lancet 386: 249-257, 2015.

5. Miyake T, Kumasawa K, Sato N, Takiuchi T, Nakamura H and Kimura T: Soluble VEGF receptor 1 (sFLT1) induces non-apoptotic death in ovarian and colorectal cancer cells. Sci Rep 6: 24853, 2016.

6. Camerin GR, Brito AB, Vassallo J, Derchain SF and Lima CS: VEGF gene polymorphisms and outcome of epithelial ovarian cancer patients. Future Oncol 13: 409-414, 2016.

7. Kim BR, Yoon K, Byun HJ, Seo SH, Lee SH and Rho SB: The anti-tumor activator sMEK 1 and paclitaxel additively decrease expression of HIF-1 $\alpha$ and VEGF via mTORC1-S6K/4E-BP-dependent signaling pathways. Oncotarget 5: 6540-6551, 2014.

8. Ganta S, Singh A, Patel NR, Cacaccio J, Rawal YH, Davis BJ, Amiji MM and Coleman TP: Development of EGFR-targeted nanoemulsion for imaging and novel platinum therapy of ovarian cancer. Pharm Res 31: 2490-2502, 2014.

9. Ranjbar R, Nejatollahi F, Nedaei Ahmadi AS, Hafezi H and Safaie A: Expression of vascular endothelial growth factor (VEGF) and epidermal growth factor receptor (EGFR) in patients with serous ovarian carcinoma and their clinical significance. Iran J Cancer Prev 8: e3428, 2015.

10. Kodigepalli KM, Dutta PS, Bauckman KA and Nanjundan M: SnoN/SkiL expression is modulated via arsenic trioxide-induced activation of the PI3K/AKT pathway in ovarian cancer cells. FEBS Lett 587: 5-16, 2013.

11. Glaysher S, Bolton LM, Johnson P, Atkey N, Dyson M, Torrance $\mathrm{C}$ and Cree IA: Targeting EGFR and PI3K pathways in ovarian cancer. Br J Cancer 109: 1786-1794, 2013.

12. Wu M, Chen X, Lou J, Zhang S, Zhang X, Huang L, Sun R, Huang P, Wang F and Pan S: TGF- $\beta 1$ contributes to CD8+ Treg induction through p38 MAPK signaling in ovarian cancer microenvironment. Oncotarget, 7: 44534-44544, 2016.

13. Wang F, Chang Z, Fan Q and Wang L: Epigallocatechin-3-gallate inhibits the proliferation and migration of human ovarian carcinoma cells by modulating p38 kinase and matrix metalloproteinase-2. Mol Med Rep 9: 1085-1089, 2014.

14. Lu M, Xiao L, Hu J, Deng S and Xu Y: Targeting of p38 mitogen-activated protein kinases to early growth response gene 1 (EGR-1) in the human paclitaxel-resistance ovarian carcinoma cells. J Huazhong Univ Sci Technolog Med Sci 28: 451-455, 2008.

15. Tong Q, Qing Y, Wu Y, Hu X, Jiang L and Wu X: Dioscin inhibits colon tumor growth and tumor angiogenesis through regulating VEGFR2 and AKT/MAPK signaling pathways. Toxicol Appl Pharmacol 281: 166-173, 2014. 
16. Qi M,Yin L, Xu L, Tao X, Qi Y,Han X, Wang C,Xu Y,Sun H,Liu K and Peng J: Dioscin alleviates lipopolysaccharide-induced inflammatory kidney injury via the microRNA let-7i/TLR4/MyD88 signaling pathway. Pharmacol Res 111: 509-522, 2016.

17. Wang Y, He QY and Chiu JF: Dioscin induced activation of p38 MAPK and JNK via mitochondrial pathway in HL-60 cell line. Eur J Pharmacol 735: 52-58, 2014.

18. Smith HO, Moon J, Wilczynski SP, Tiersten AD, Hannigan EV, Robinson WR, Rivkin SE, Anderson GL, Liu PY and Markman M: Southwest oncology group trial S9912: Intraperitoneal cisplatin and paclitaxel plus intravenous paclitaxel and pegylated liposomal doxorubicin as primary chemotherapy of small-volume residual stage III ovarian cancer. Gynecol Oncol 114: 206-209, 2009.

19. Noonan AM, Bunch KP, Chen JQ, Herrmann MA, Lee JM, Kohn EC, O'Sullivan CC, Jordan E, Houston N, Takebe N, et al: Pharmacodynamic markers and clinical results from the phase 2 study of the SMAC mimetic birinapant in women with relapsed platinum-resistant or -refractory epithelial ovarian cancer. Cancer 122: 588-597, 2016.

20. Adham SA, Sher I and Coomber BL: Molecular blockade of VEGFR2 in human epithelial ovarian carcinoma cells. Lab Invest 90: 709-723, 2010

21. Lu W, Chen H, Yel F, Wang F and Xie X: VEGF induces phosphorylation of STAT3 through binding VEGFR2 in ovarian carcinoma cells in vitro. Eur J Gynaecol Oncol 27: 363-369, 2006.

22. Barua A, Yellapa A, Bahr JM, Machado SA, Bitterman P, Basu S, Sharma S and Abramowicz JS: VEGFR2-targeted ultrasound imaging agent enhances the detection of ovarian tumors at early stage in laying hens, a preclinical model of spontaneous ovarian cancer. Ultrason Imaging 37: 224-237, 2015.

23. Ye J, Chen W, Wu ZY, Zhang JH, Fei H, Zhang LW, Wang YH, Chen YP and Yang XM: Upregulated CTHRC1 promotes human epithelial ovarian cancer invasion through activating EGFR signaling. Oncol Rep 36: 3588-3596, 2016.
24. Baron AT, Wilken JA, Haggstrom DE, Goodrich ST and Maihle NJ: Clinical implementation of soluble EGFR (sEGFR) as a theragnostic serum biomarker of breast, lung and ovarian cancer. IDrugs 12: 302-308, 2009.

25. Zhao J, Klausen C, Qiu X, Cheng JC, Chang HM and Leung PC: Betacellulin induces slug-mediated down-regulation of E-cadherin and cell migration in ovarian cancer cells. Oncotarget 7: 28881-28890, 2016.

26. Hsieh MJ, Tsai TL, Hsieh YS, Wang CJ and Chiou HL: Dioscin-induced autophagy mitigates cell apoptosis through modulation of PI3K/Akt and ERK and JNK signaling pathways in human lung cancer cell lines. Arch Toxicol 87: 1927-1937, 2013.

27. Malm SW, Hanke NT, Gill A, Carbajal L and Baker AF: The anti-tumor efficacy of 2-deoxyglucose and D-allose are enhanced with p38 inhibition in pancreatic and ovarian cell lines. J Exp Clin Cancer Res 34: 31, 2015.

28. Xu W, Gu J, Ren Q, Shi Y, Xia Q, Wang J, Wang S, Wang Y and Wang J: NFATC1 promotes cell growth and tumorigenesis in ovarian cancer up-regulating c-Myc through ERK1/2/p38 MAPK signal pathway. Tumour Biol 37: 4493-4500, 2016.

29. Watson JL, Greenshields A, Hill R, Hilchie A, Lee PW, Giacomantonio CA and Hoskin DW: Curcumin-induced apoptosis in ovarian carcinoma cells is p53-independent and involves p38 mitogen-activated protein kinase activation and downregulation of Bcl-2 and survivin expression and Akt signaling. Mol Carcinog 49: 13-24, 2010.

30. Zhang B, Wang X, Cai F, Chen W, Loesch U and Zhong XY: Antitumor properties of salinomycin on cisplatin-resistant human ovarian cancer cells in vitro and in vivo: Involvement of p38 MAPK activation. Oncol Rep 29: 1371-1378, 2013.

31. Buldak RJ, Polaniak R, Buldak L, Mielanczyk L, Kukla M, Skonieczna M, Dulawa-Buldak A, Matysiak N and Zwirska-Korczala K: Exogenous administration of visfatin affects cytokine secretion and increases oxidative stress in human malignant melanoma Me45 cells. J Physiol Pharmacol 64: 377-385, 2013. 